\title{
RELAÇÃO FAMÍLIA-TRABALHO reestruturação produtiva e desemprego
}

\author{
Lilia Montali
}

Resumo: A análise trata de maneira articulada as transformações da família e do mercado de trabalho sob o processo recente de reestruturação das atividades econômicas da Região Metropolitana de São Paulo. No contexto de pequena expansão das oportunidades de trabalho observada nos anos 90 e de crescente desemprego dos principais mantenedores da família, novos arranjos familiares de inserção no mercado de trabalho passaram a ser articulados.

Palavras-chave: família e trabalho; reestruturação produtiva; desemprego.

\begin{abstract}
This essay provides a detailed analysis of the transformation in the family and the labor market as a result of the recent restructuring of economic activities in the Metropolitan Region of São Paulo. New familial configurations emerged as the result of limited expansion of employment opportunities during the 1990's and the growing unemployment rates of heads of household.

Key words: family and work; productive restructuring; unemployment.
\end{abstract}

$\mathrm{N}$ este artigo sobre as mudanças na relação família-trabalho, são tratadas conjuntamente as influências recíprocas da estruturação das atividades produtivas e da estruturação das famílias. Considerando a articulação entre produção e reprodução através da divisão sexual do trabalho e a mútua influência entre essas duas esferas, este estudo busca conhecer de que maneiras as transformações nas formas de produção e gestão, que afetam as oportunidades diferenciadas de emprego de homens e de mulheres no mercado de trabalho, nos anos 90, manifestam-se na unidade familiar.

Indaga-se também sobre as alterações da relação família-trabalho relativas às atuais transformações das atividades econômicas e as possíveis consequiências destas na mudança das relações hierárquicas na família.

Os resultados dessa pesquisa vêm mostrando que ocorreram, na década de 90, mudanças no padrão de incorporação pelo mercado de trabalho e aumento do desemprego, que afetam diferentemente os componentes das famílias, identificados por sua posição no interior destas bem como por gênero e idade. Essas mudanças expressam-se em alterações nos arranjos familiares de inserção no mercado de trabalho, com especificidades observadas nos diferentes momentos do ciclo de vida da família. Os rearranjos de inserção refletem-se, como se verá, inclusive na modificação do peso da contribuição de cada membro do grupo doméstico na composição da renda familiar.

Ainda que este trabalho detenha-se mais especificamente sobre as novas tendências encontradas na relação família-trabalho nos anos 90, os resultados e reflexões aqui apresentados incorporam conhecimento acumulado de três estudos de caso para períodos específicos:

- 1981-83, momento de crise econômica do início dos anos 80;

- 1990-94, intensificação da reestruturação produtiva na Região Metropolitana de São Paulo, sendo que os dois primeiros anos (1990 e 1991) foram de crise econômica e os últimos de início da recuperação sem recuperação do emprego;

- 1997-99, momento em que, sob a reestruturação produtiva, ocorreu nova crise econômica, resultando no recrudescimento do desemprego. ${ }^{1}$

O primeiro período em que se analisou a relação família-trabalho e sua transformação (1981-83) tem como marcas a crise econômica e o momento de acentuação da 
entrada da mulher no mercado de trabalho, iniciada na metade da década anterior. ${ }^{2}$ Foram analisadas a inserção diferenciada dos componentes das famílias no mercado de trabalho e sua mobilização no momento da crise econômica. Procurou-se, através da inserção e da mobilização destes, identificar rearranjos inovadores na relação família-trabalho dominante, indicativos de mudanças na divisão sexual do trabalho na família. Nessa mesma pesquisa, analisou-se outra conjuntura recessiva mais recente (1990-91), com base nos dados da PED (Pesquisa de Emprego e Desemprego), realizada pela Fundação Seade, encontrando-se semelhanças na mobilização dos componentes da família na crise. Entre as semelhanças de mobilização familiar encontradas na comparação entre as crises do início dos anos 80 e do começo da década de 90, a maior inserção da mulher no mercado de trabalho - tanto cônjuges como filhas -, que ocorreu no mesmo momento em que, sob as restrições colocadas por este, cresce o desemprego masculino. ${ }^{3}$ Esta e outras tendências que se acentuam no período são interpretadas como indicativas de rupturas na possibilidade concreta de realização do padrão de família mantido pelo chefe provedor, especialmente nas conjunturas recessivas. Os resultados de pesquisa ofereceram sustentação para indicar que o processo de mudança na relação família-trabalho põe em questão a figura do provedor, culturalmente atribuída ao chefe da família, expressando possíveis transformações nas relações internas de hierarquia e de poder.

Dessa maneira, a pesquisa sobre o início dos anos 80 detectou processos e suscitou indagações, dando origem aos estudos subseqüentes sobre os anos 90 .

No segundo período, 1990-94, as mudanças na relação família-trabalho foram analisadas sob a reestruturação produtiva. ${ }^{4}$ Em 1990, intensificou-se o processo de inovações produtivas e organizacionais na Região Metropolitana de São Paulo, pioneira nesse processo no Brasil; em 1994, a reestruturação continuou operando e já se tornavam evidentes seus efeitos na deterioração das relações de trabalho e no desemprego. Esse período estudado é relevante por possibilitar apreender aspectos das estratégias de vinculação das famílias ao mercado de trabalho sob o impacto do início da intensificação da reestruturação produtiva.

Buscava-se identificar nesse estudo quais indicações de mudança percebidas no estudo dos anos 80 eram temporárias e quais eram mais duradouras, além dos momentos de conjuntura de crise. Tinha-se por hipótese que, devido ao fato de os anos 80 e o início dos 90 terem sido marcados primordialmente pela conjuntura recessiva (embora com alguns momentos de expansão), as mudanças na relação família e trabalho anteriormente identificadas seriam aceleradas e consolidadas, favorecendo as transformações nas relações internas das famílias.

Quando considerados os anos de 1981 e 1990, verifica-se que os arranjos familiares de inserção no mercado de trabalho eram semelhantes. No entanto, a comparação entre 1990 e 1994 evidencia, para este último ano, rearranjos de inserção com especificidades nos diferentes tipos de família, ${ }^{5}$ o que, certamente, já expressava os efeitos da reestruturação produtiva e dos novos padrões de absorção da força de trabalho sobre a família e a relação família-trabalho (Montali, 2000b).

A última pesquisa ${ }^{6}$ trata do mesmo tema, analisando tais processos no período 1997-99, quando recrudesceu o desemprego. A partir de 1998, acrescenta-se ao elevado desemprego a queda da renda dos ocupados e da renda familiar per capita. Se nos anos em que já se faziam sentir de maneira inequívoca os efeitos da reestruturação organizacional e produtiva foram identificados arranjos de inserção no mercado de trabalho, nesta última pesquisa evidenciaram-se mudanças que configuram rearranjos.

Assim, a partir de 1994, diferenciando-se dos arranjos anteriormente encontrados em 1981 e em 1990, os rearranjos refletem o deslocamento da responsabilidade pela manutenção da família dos principais mantenedores identificados para cada tipo de família nas pesquisas anteriores (Montali, 1995, 1998) para outros componentes da família, especialmente para a mulher-cônjuge, bem como maior partilhamento dessa responsabilidade.

Essa nova tendência delineia-se em face da redução dos postos de trabalho, principalmente para ocupações predominantemente masculinas, resultando em crescente desemprego dos até então principais mantenedores das famílias (chefes e filhos masculinos e filhas maiores que 18 anos), e diante das maiores dificuldades de absorção encontradas pelos jovens a partir de 1992. Embora com especificidades nos diversos tipos de família, foi possível identificar duas tendências gerais. A primeira, no caso de famílias estruturadas em torno do casal, expressa-se na crescente participação da mulher-cônjuge entre os ocupados da família, na redução do peso do chefe masculino entre estes e na diminuição da participação dos filhos. Uma exceção entre as famílias conjugais é encontrada para aquelas na etapa da "velhice", considerando-se o ciclo de vida familiar - ou seja, de casais com mais de 50 anos -, com a presença de filhos residentes, em que, comparati- 
vamente ao verificado em 1981-83 e 1990, cresceu a participação do chefe masculino entre os ocupados da família de forma concomitante à redução da participação dos filhos adultos, afetados pelo desemprego.

A segunda tendência observada refere-se às famílias com chefia feminina sem cônjuge, nas quais a participação da chefe entre os ocupados da família aumenta em decorrência da menor absorção dos filhos e parentes jovens pelo mercado de trabalho.

Observa-se, até o final da década de 90, a continuidade progressiva desse padrão de rearranjos familiares de inserção no mercado de trabalho e de mudanças na relação família-trabalho.

Um dos resultados mais relevantes dessas pesquisas, para o estudo da relação família-trabalho, refere-se ao conhecimento sobre os efeitos dos novos padrões de incorporação da força de trabalho pelo mercado, que incidem sob a reestruturação produtiva, modificando as possibilidades de emprego de determinados componentes, identificados por sua posição na família e atribuições específicas, e os novos arranjos de inserção no mercado de trabalho, que passam a ser articulados nos diferentes tipos de família diante de tais restrições e oportunidades. Deve-se acrescentar que os resultados apontados neste artigo para determinados períodos se confirmam como tendência para a década, segundo de todo o período de 1985 a 2000, recentemente realizada, utilizando a base de dados da Pesquisa de Emprego e Desemprego, da Fundação Seade (Montali, 2002).

Estas análises identificam as tendências na década de 90 para a Região Metropolitana de São Paulo e são, muito possivelmente, aplicáveis também a outras metrópoles brasileiras, desde que adequadamente contextualizadas.

\section{MUDANÇAS NO MERCADO DE TRABALHO: REFLEXOS SOBRE AS CONDIÇÕES DE VIDA E O EMPREGO}

As duas últimas décadas têm sido de profundas transformações nas atividades econômicas da Região Metropolitana de São Paulo, principal centro industrial do país, como resultado de processos relacionados entre si, tais como a desconcentração industrial, o desenvolvimento do terciário e a reestruturação produtiva. ${ }^{7}$

Resultam destas transformações a redução do emprego industrial, a expansão e a consolidação das atividades de serviços e a deterioração das condições de inserção no mercado de trabalho na Região Metropolitana, expressa pela redução dos empregos regulamentados e pela elevação do patamar das taxas de desemprego. ${ }^{8}$

As atividades do terciário diversificam-se e este consolida-se, concentrando na região atividades altamente sofisticadas. Diversos processos estão envolvidos na expansão do terciário. Por um lado, a centralidade que a região passa a ter a partir da década de 80 , acentuando-se na de 90 ao concentrar atividades de gestão e do terciário superior, gera empregos de qualidade. ${ }^{9}$ Também novas possibilidades de ocupações no terciário foram geradas pela consolidação, nos anos 90, da inclusão da Região Metropolitana de São Paulo na rede de cidades mundiais, através da qual se articulam as relações com o mercado internacionalizado. ${ }^{10}$

Por outro lado, a reestruturação produtiva, ao subcontratar atividades desenvolvidas em áreas de apoio e naquelas produtivas, acarreta a criação de setores informais modernos. Com a terceirização e a subcontratação da produção e dos serviços, a informalização passa a crescer rapidamente e, através da expansão dos pequenos negócios se estabelece uma rede de produtores e de prestadores de serviços organizada sob relações de trabalho fortemente precárias (Dedecca; Baltar, 1997).

Os dados da Pesquisa de Emprego e Desemprego, da Fundação Seade, evidenciam, a partir de 1989 - ano tomado como referência para a análise dos efeitos da reestruturação da produção e das formas de gestão do trabalho na Região -, a progressiva redução da participação da indústria na composição do nível de emprego regional e o aumento da importância do emprego nos serviços. Os postos de trabalho do setor serviços, incluindo-se os do comércio e dos serviços, representavam $56 \%$ das ocupações em 1989 e cerca de 69\% em 2000. O emprego industrial correspondia, em 1989, a 33\% da força de trabalho ocupada, diminuindo para 19,6\%, em 1999, e 19,9\%, em 2000 (Fundação Seade, 2001).

Uma das conseqüências dessa alteração na composição do emprego por setor, apontada por estudos sobre o mercado de trabalho, é a piora na qualidade do emprego. O emprego industrial, predominantemente regulamentado, passou a ser substituído, na trajetória de muitos dos que perderam esses empregos, por ocupações autônomas ou temporárias caracterizadas por maior instabilidade (Fundação Seade, 1998a, b; Cardoso; Comin; Guimarães, 2001).

Dessa maneira, a reestruturação produtiva e o baixo nível da atividade econômica elevaram as taxas de desemprego na região e promoveram a precarização das relações de trabalho. 
O desemprego, nos anos 90, assumiu características específicas, atingindo patamares mais elevados que na segunda metade da década anterior (Montali, 2000b; Brandão; Montagner, 1996). A partir de 1990, quando começaram a ser eliminados postos de trabalho na RMSP como conseqüência da reorganização das formas de produção e gestão e da abertura da economia ao comércio internacional, a taxa de desemprego superava os $10 \%$ da PEA, recrudescendo, em 1992, quando ultrapassou os 15\%. Entre 1992 e 1997, as taxas de desemprego total registradas pela Pesquisa de Emprego e Desemprego, da Fundação Seade, oscilaram ao redor de $16 \%$ da população economicamente ativa ${ }^{11} \mathrm{e}$, com exceção de 1995, são bastante próximas daquelas verificadas durante a crise do início da década de 80 , ou seja, de $16,0 \%$ em 1981 e de 16,5\% em 1983 (Dieese, 1984). ${ }^{12}$

Outro patamar mais elevado de desemprego se estabeleceu a partir de maio de 1997, na Região Metropolitana de São Paulo. Em 1998, a média anual chegou a 18,2\% e, em 1999, alcançou 19,3\%, "superando mais uma vez todos os patamares anuais registrados na PED" (Fundação Seade, 2000).

A deterioração das condições de inserção no mercado de trabalho, na década de 90 , incluindo o aumento do desemprego e dos postos de trabalho precários, provocou a queda dos rendimentos do trabalho para os ocupados, com maior intensidade nos últimos anos, quando novamente ocorreu redução da atividade econômica em âmbito nacional. Entre 1995 e 2000, o rendimento real médio dos ocupados reduziu-se em $14,3 \%$ (Fundação Seade, 2000). Quando considerado o período 1989-2000, a queda correspondeu a cerca de $20 \%$, porque, mesmo com a recuperação do rendimento dos ocupados entre 1994 e 1996, não foram atingidos os níveis vigentes em 1989 na Região Metropolitana.

As consequiências das alterações nas possibilidades de inserção no mercado de trabalho e da queda dos rendimentos provenientes do trabalho são evidentes sobre o rendimento familiar médio e per capita. Foi possível identificar três movimentos na evolução do rendimento familiar per capita a partir de 1989: caiu acentuadamente entre 1989 e 1992, correspondendo à recessão do início da década; elevou-se entre 1993 e 1995 como efeito da recuperação do crescimento de economia; e após 1994, também aumentou como resultado do plano de estabilização. Em 1996 e 1997, o rendimento estabilizou-se; voltando a cair a partir de 1998, com continuidade em 1999. Desse movimento, resultou perda de poder aquisitivo para as

\section{GRÁFICO 1}

Rendimento Familiar per Capita Médio (1)

Região Metropolitana de São Paulo-1986-2000

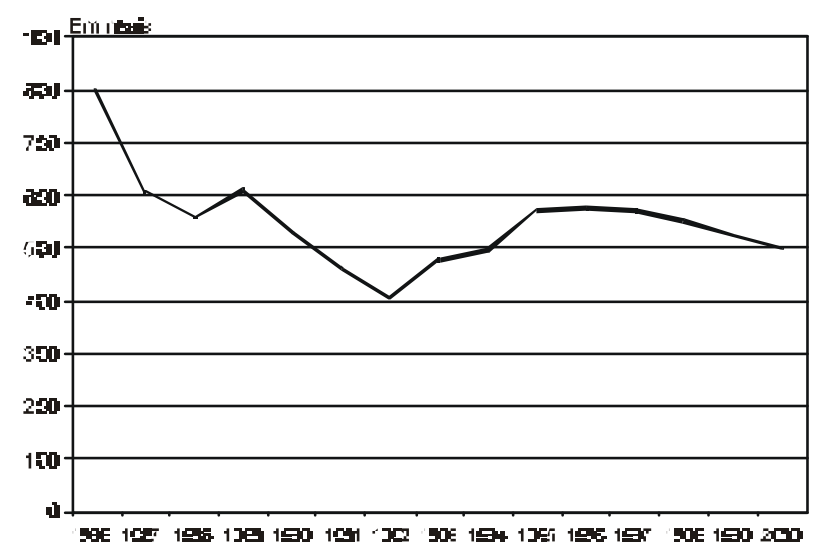

Fonte: Fundação Seade - Dieese - Pesquisa de Emprego e Desemprego. Elaboração: Montali (2002:8).

(1) Em reais de dezembro de 2000 - ICV-Dieese.

famílias metropolitanas, pois, entre 1989 e 2000, o rendimento familiar per capita médio retraiu-se em $18 \%$ (Montali, 2002).

Na década de 90, a contribuição para renda familiar oriunda do trabalho das mulheres-cônjuges possibilitou menor deterioração dos rendimentos familiares (Troncoso, 2000). Mesmo que o desemprego seja elevado e crescente para todos os componentes da família, entre 1992 e 1997 a mulher-cônjuge foi o único membro entre os ocupados da família a apresentar tendência ascendente no valor real do rendimento do trabalho; a partir desse ano passou a sofrer perdas.

A análise dos dados gerados pela PED (Fundação Seade, 2000) evidencia que, em 1998 e 1999, todos os componentes ocupados da família tiveram reduções no rendimento real. A comparação dos dados de 1999 com aqueles referentes a 1989, mostra que, enquanto a queda no rendimento do total dos ocupados foi de $17,9 \%$, para as cônjuges ocupadas essa redução foi menos acentuada $(4,2 \%)$, bem como menor que observada para os demais componentes ocupados da família. A retração, no mesmo período, da renda dos chefes de família ocupados foi de $22,7 \%$ e a dos filhos correspondeu a 22,1\% (Montali, 2000b).

Outro aspecto a ressalvar no período entre 1989 e 1999, relativo às condições de vida na Região Metropolitana de São Paulo, é que, apesar do plano de estabilização a partir de 1994, não houve significativa redução na desigualdade 
da distribuição da renda do trabalho. Do total da massa de rendimentos do trabalho gerada em 1999, os $10 \%$ dos ocupados mais pobres apropriaram-se de apenas $1,1 \%$, os $50 \%$ mais pobres ficaram com $16,3 \%$, enquanto os $10 \%$ mais ricos apropriaram-se de 42,3\% (Fundação Seade, 2000). Essa situação é muito semelhante à observada em 1989, embora tenha havido alguma elevação da proporção apropriada pelos mais pobres. Naquele ano, os $10 \%$ dos ocupados mais pobres alcançaram $0,4 \%$ da massa de rendimentos e os $50 \%$ mais pobres ficaram com $14,6 \%$, enquanto a parcela apropriada pelos $10 \%$ mais ricos era de $41,4 \%$, um pouco menor que a registrada em 1999, significando que, no período, houve certa ampliação na participação destes no total dos rendimentos do trabalho.

\section{Mudanças no Emprego por Gênero}

O processo de reestruturação produtiva na Região Metropolitana de São Paulo, nos anos 90, vem restringindo mais fortemente os postos de trabalho masculinos. As tendências observadas na primeira metade da década são de acentuada queda nas taxas de ocupação masculina, que se mantêm mais elevadas que as femininas, e de manutenção das taxas de ocupação femininas oscilando num mesmo patamar (Brandão; Montagner, 1996). Observa-se, na segunda metade da década, continuidade da tendência de queda mais acentuada nas taxas de ocupação masculina e, a partir de 1997, para ambos os sexos, evidenciando a redução das possibilidades de absorção pelo mercado de trabalho.

Também é distinto o comportamento das taxas de participação para homens e mulheres. Enquanto a taxa de participação feminina cresce progressivamente, a dos homens, mais elevada, apresenta tendência de queda. Em decorrência desse comportamento, a expansão da taxa de participação regional na década - que passou de $60,2 \%$ em 1990 para 61,6\% em 1998 e 62,2\% em 1999 - é atribuída à participação feminina (Fundação Seade, 2000).

Os estudos sobre mercado de trabalho e gênero vêm constatando, em outros países da América Latina e da Europa, durante os anos 90, tendência semelhante de crescimento da taxa de participação feminina concomitante à queda daquela referente aos homens (Posthuma; Lombardi, 1997; Hirata; Humphrey, 1994; Abramo, 2000; González de la Rocha, 1997).

Os efeitos diferenciados da reorganização das atividades econômicas sobre o emprego masculino e feminino, na RMSP, podem ser mais bem explicitados através dos conceitos da divisão sexual do trabalho e das relações de gênero.
Apesar de importantes mudanças na inserção das mulheres no mercado de trabalho, principalmente na segunda metade dos anos 90, tais como a entrada em novos postos de trabalho antes tipicamente masculinos e a maior participação entre os profissionais de nível superior, em profissões de maior prestígio com predomínio masculino (Bruschini; Lombardi, 2000), grande parte das mulheres concentra-se em ocupações tradicionalmente femininas. No decorrer dos anos 90, persiste a "sexualização" das ocupações, ou seja, são mantidos funções e setores de atividade que concentram diferencialmente homens e mulheres (Bruschini, 1994) e que expressam a divisão sexual do trabalho, que opera tanto na família como no mercado de trabalho.

Este fato favoreceu o emprego feminino. Por um lado, no processo de reorganização produtiva e organizacional, os postos de trabalho ocupados por mulheres foram menos afetados do que os ocupados pelos homens. Isto porque, em primeiro lugar, o setor da atividade econômica que mais sofreu retração de empregos na região, nos anos 90, foi o industrial e, especialmente, o ramo metal-mecânico, que empregava predominantemente homens, e, em segundo lugar, porque, por ocuparem poucos cargos de chefia, as mulheres foram menos atingidas pela redução das hierarquias das empresas e também pela inovação de processos, com a introdução de novos equipamentos, um vez que muito poucas operavam máquinas. Em ambos os casos, trabalhadores do sexo masculino foram afetados por eliminação de postos ou por substituição (Matesco, 1995; Lavinas; Matesco, 1996).

Por outro lado, a divisão sexual do trabalho, que atua conjuntamente no mercado de trabalho e nas relações familiares definindo os lugares de homens e de mulheres (Barrère-Maurisson, 1992), favorece que sejam mais frágeis as formas de vinculação das mulheres ao mercado. Historicamente, é menor a proporção das mulheres entre os assalariados e, na década de 90 , foi crescente sua vinculação ao mercado de trabalho através do trabalho autônomo, do assalariamento sem registro em carteira de trabalho e em serviços domésticos (Montali, 2000b; Montali; Lopes, 2002). Não se pode deixar de registrar que também os trabalhadores do sexo masculino sofreram o processo de fragilização das formas de vinculação ao mercado de trabalho nos anos 90, com a perda de postos de trabalho regulamentados.

Como mencionado anteriormente, o setor de serviços vem se expandindo nas duas últimas décadas na região metropolitana e é o setor de atividade que concentra a 
maior parcela da força de trabalho feminina, embora venha ampliando oportunidades de absorção também para os homens. Mesmo considerando-se a diversidade do setor terciário, neste são maiores as possibilidades de vinculações precárias ao mercado de trabalho, reduzindo, principalmente para as mulheres, as chances de inserção em empregos de qualidade num período de crescimento de sua participação no mercado de trabalho.

As tendências de absorção pelo mercado de trabalho aqui sintetizadas expressam as profundas modificações nas formas de inserção no mercado na Região Metropolitana de São Paulo e refletem-se nos arranjos familiares para garantir a sobrevivência. A crescente participação das mulheres no mercado de trabalho é um fato importante nas mudanças observadas nos arranjos familiares de inserção articulados pelas famílias nos anos 90. Alterações nos valores em relação ao papel da mulher na sociedade e na estruturação dos núcleos domésticos têm aumentado a disponibilidade desta, em todas as idades e posições na família, para o trabalho remunerado.

Embora as mudanças nas características da composição familiar integrem esse processo com acentuação, no período, de algumas tendências na sua estruturação, da continuidade da redução no seu tamanho e da mais significativa redução na proporção de filhos menores de dez anos, considera-se que foi a mudança ocorrida no padrão de absorção da força de trabalho vigente na década de 90 , em relação ao início dos anos de 80, que afetou mais profundamente os arranjos de inserção dos componentes da família no mercado de trabalho.

\section{Mudanças na Relação Família-Trabalho}

As análises a partir da unidade familiar possibilitam conhecer as respostas das famílias e dos sujeitos com suas atribuições familiares às diferentes conjunturas que condicionam as possibilidades de emprego. Dessa maneira, foi possível identificar uma nova tendência na articulação dos arranjos familiares de inserção no mercado na década de 90, como decorrência da redução dos postos de trabalho, principalmente para ocupações predominantemente masculinas, o que resultou em crescente desemprego daqueles que eram os principais mantenedores das famílias, ou seja, os chefes masculinos e filhos, bem como filhas maiores de 18 anos. Deve-se acrescentar que, a partir de 1992, acentuaram-se as dificuldades de absorção dos jovens pelo mercado de trabalho na região metropolitana (Pochmann, 1998).
Como mencionado nos itens anteriores, os arranjos de inserção no mercado de trabalho articulados pelos componentes das famílias nos anos em que já se faziam sentir os efeitos da reestruturação organizacional e produtiva evidenciam mudanças que configuram rearranjos. Essa conclusão está fundamentada na alteração verificada entre os componentes ocupados na família, sem que houvesse alteração no número médio de ocupados segundo tipo de família, entre 1990 e 1994, e, pelo contrário, diminuindo entre esse período e o final da década.

Diferenciando-se dos anteriormente encontrados, os novos arranjos refletem maior partilhamento da responsabilidade da manutenção da família entre seus componentes, com o deslocamento de parte dessa responsabilidade dos principais mantenedores, identificados para cada tipo de família nas pesquisas dos períodos 19811983 e 1990 (Montali, 1995) para outros membros da família.

Os arranjos familiares de inserção no mercado de trabalho observados nas análises dos anos 90 evidenciam: semelhanças em relação àqueles encontrados no início da década de 80 e diferenciação quanto aos identificados em 1994 e no final da década (1997, 1998 e 1999).

Com base em análises sobre os arranjos familiares, supõe-se que, além da redução da taxa de ocupação no período e da deterioração do emprego na Região Metropolitana de São Paulo, o empobrecimento para os diferentes tipos de família está relacionado aos rearranjos de inserção familiar que estão ocorrendo e às diferentes vantagens e restrições de inserção no mercado que cada componente encontra - condicionadas que são pelo gênero, idade e posição na família (Montali, 2000a) -, considerando-se que não existe "permutabilidade" entre estes para a inserção no mercado de trabalho (Hirata; Humphrey, 1994).

Como um exemplo desse fato, a mais elevada presença da mulher-cônjuge entre os ocupados da família em todos os tipos de família, especialmente a partir de 1994, não resulta em aumento equivalente de sua participação na composição da renda familiar, como pode-se observar nos Gráficos 2 e 3 . Isso decorre da qualidade do trabalho dessa componente da família. A análise das formas predominantes de inserção das mulheres-cônjuges mostra que mais da metade delas encontra-se vinculada de formas precárias ao mercado de trabalho. Apenas cerca de $41 \%$ delas estão em situação de assalariamento regulamentado, a mais baixa proporção quando comparada aos demais componentes ocupados da família (Montali, 2000b). 
A metodologia desenvolvida por este estudo, através da análise dos arranjos familiares de inserção no mercado de trabalho considerando-se o tipo de família, possibilita verificar, no grupo familiar, alguns dos efeitos das alterações das possibilidades de emprego oferecidas pelo mercado de trabalho e das novas características dos desempregados, como decorrência do baixo ritmo de expansão da economia e da mudança do padrão de incorporação da força de trabalho introduzido a partir da reestruturação produtiva e organizacional nos diversos setores de atividade.

A análise das taxas familiares de participação, ocupação, desemprego e inatividade para o período 1990-94 evidencia que, apesar do aumento da disponibilidade de seus componentes para o mercado de trabalho, indicado pela crescente taxa de participação em todos os tipos de família, não ocorreu expansão da absorção desses contingentes pelo mercado de trabalho (expressa pelas taxas de ocupação estáveis), resultando em mais elevadas taxas de desemprego em 1994. Como agravante dessa situação, entre 1997 e 1999 ocorreram aumento da taxa de participação e queda da taxa de ocupação para o total da PIA e para cada um dos tipos de família pesquisados, resultando em taxas de desemprego crescentes, em patamares antes não conhecidos na região metropolitana (Tabela 1).

Os rearranjos de inserção dos componentes da família no mercado de trabalho diferenciam-se por tipos de família, mas o mais freqüente em praticamente todos os tipos é o caso do aumento da participação da mulher-cônjuge e da mulher-chefe entre os ocupados da família e, no caso da família com a presença de filhos na etapa final do ciclo de vida familiar, o aumento da participação do chefe e da cônjuge entre os ocupados, que se dá ao mesmo tempo em que cresce o desemprego dos filhos adultos.

Os atuais arranjos e rearranjos de inserção dos componentes da família no mercado de trabalho são definidos articuladamente pela dinâmica da economia e das relações

TABELA 1

Taxas Específicas de Participação, Ocupação, Desemprego e Inatividade, segundo Tipos de Família Região Metropolitana de São Paulo-1990-1999

Em porcentagem

\begin{tabular}{|c|c|c|c|c|}
\hline Tipos de Família & Participação (1) & Ocupação (2) & Desemprego (3) & Inatividade (4) \\
\hline \multicolumn{5}{|l|}{1990} \\
\hline Total (5) & 58,0 & 52,0 & 10,3 & 41,3 \\
\hline Casal sem Filhos & 51,9 & 47,3 & 8,8 & 47,5 \\
\hline Casal de até 34 Anos com Filhos e Parentes & 59,6 & 54,1 & 9,2 & 40,0 \\
\hline Casal de 35 a 49 Anos com Filhos e Parentes & 55,4 & 49,9 & 10,0 & 43,7 \\
\hline Casal de 50 Anos e Mais com Filhos e Parentes & 58,0 & 52,0 & 10,3 & 41,8 \\
\hline Chefe Feminino sem Cônjuge & 61,8 & 53,6 & 13,3 & 37,4 \\
\hline \multicolumn{5}{|l|}{1994} \\
\hline Total (5) & 60,7 & 51,7 & 14,8 & 39,2 \\
\hline Casal sem Filhos & 56,4 & 51,0 & 9,5 & 43,4 \\
\hline Casal de até 34 Anos com Filhos e Parentes & 63,4 & 55,7 & 12,0 & 36,6 \\
\hline Casal de 35 a 49 Anos com Filhos e Parentes & 58,9 & 49,9 & 15,3 & 40,9 \\
\hline Casal de 50 Anos e Mais com Filhos e Parentes & 59,5 & 52,1 & 12,4 & 40,4 \\
\hline Chefe Feminino sem Cônjuge & 60,3 & 48,2 & 19,9 & 39,6 \\
\hline \multicolumn{5}{|l|}{1999} \\
\hline Total (5) & 62,5 & 49,8 & 19,3 & 37,4 \\
\hline Casal sem Filhos & 62,6 & 54,2 & 13,5 & 37,1 \\
\hline Casal de até 34 Anos com Filhos e Parentes & 66,2 & 53,2 & 19,6 & 33,7 \\
\hline Casal de 35-49 Anos com Filhos e Parentes & 60,6 & 47,8 & 21,1 & 39,3 \\
\hline Casal de 50 Anos e Mais com Filhos e Parentes & 59,7 & 47,8 & 20,0 & 40,3 \\
\hline Chefe Feminino sem Cônjuge & 60,2 & 46,0 & 23,6 & 39,6 \\
\hline
\end{tabular}

Fonte: Fundação Seade. Pesquisa de Condições de Vida - PCV 1990 e 1994; Fundação Seade - Dieese. Pesquisa de Emprego e Desemprego - PED (trimestre maio/jun./jul. 1999). Elaboração: Montali (2000).

(1) PEA/PIA

(2) Ocupados/PIA.

(3) Desempregados/PEA

(4) Inativos/PIA.

(5) Inclui outras configurações familiares.

Nota: A PIA inclui os não informados da condição de ocupação. 
familiares e de gênero, assumindo especificidades nos diferentes tipos de família, afetados pela composição predominante da etapa do ciclo de vida familiar.

Assim, no arranjo de inserção predominante na família do tipo "casal sem filhos", ${ }^{13}$ o chefe é o principal responsável pela manutenção da família. Ele representa mais da metade dos componentes ocupados e contribui com a maior parcela da renda familiar. Houve, entretanto, uma mudança no padrão observado para a década de 80 , quando comparados os anos 1990 e 1994, que persiste no final da década: a proporção de chefes entre os ocupados da família diminuiu de 63,8\%, em 1990, para 56,4\%, em 1994 (Montali, 1998), mantendo-se em torno de 57\%, nos anos finais da década (Gráfico 2). A mulher-cônjuge apresentou, entre 1990 e 1994, significativo crescimento entre os ocupados, quando passou de $32,7 \%$ para $36,5 \%$ destes, continuando nesse patamar no período 1997-99.

Embora tenha ocorrido aumento da taxa de desemprego familiar, houve, nos anos analisados da década, progressiva mobilização dos componentes desse tipo da família na busca por inserção no mercado de trabalho, como evidencia o conjunto de taxas da Tabela 1. Ocorreram aumento nas taxas familiares de participação, de ocupação e de desemprego e progressiva redução da inatividade. Entre 1990 e 1994, houve expansão do desemprego do chefe e redução em suas taxas de participação e de ocupação. Em movimento contrário, apresentaram crescimento as taxas de participação e de ocupação das cônjuges e parentes. Oscilação nesse arranjo, que envolve basicamente o casal, foi verificada quando diminuiu a taxa de ocupação da cônjuge de 45\%, em 1996, para 42\%, em 1998 , retornando ao patamar de $45 \%$ em 1999 , com reflexos na presença desse componente entre os ocupados da família, bem como em sua contribuição para a composição da renda familiar (Gráficos 2 e 3).

A participação do chefe masculino, como mencionado anteriormente, compõe a maior parte da renda familiar nesse tipo de família: cerca de 72\%, a partir de 1994. Houve, entre 1990 e 1994, redução no peso de sua contribuição (de $77,5 \%$ para $73 \%$ ) e crescimento da participação da cônjuge $(19,8 \%$ para $22 \%)$ e dos parentes $(2,7 \%$ para $5 \%$ ). A contribuição da cônjuge para a renda familiar muda de patamar no decorrer dos anos 90: 19,8\% em 1990, 21,8\%, em 1994, mantendo o crescimento até o final da década, quando atingiu 28,8\% (Gráfico 3).

Dessa maneira, o arranjo desse tipo de família na década é centrado no casal, com maior participação do homem. A comparação com o arranjo que predominava em
1981, nesse tipo de família, mostra que ocorre uma alteração na definição dos responsáveis pela manutenção das famílias. A redução relativa da participação do homem entre os ocupados da família e o crescimento daquela referente à mulher-cônjuge sugerem uma tendência de maior partilhamento na responsabilidade pela manutenção da família.

Nas famílias de "casais de até 34 anos com filhos" é encontrada situação semelhante de mobilização dos componentes da família nesse período, em que se observa elevação da taxa de ocupação, além da taxa de participação, entre 1990 e 1994, estabilizando-se nos dois últimos anos da década (Tabela 1). Como no tipo anterior, houve pequeno acréscimo no número médio de ocupados da família e no número de pessoas com algum tipo de rendimento entre 1990 e 1994 (Montali, 1998), bem como pequena redução em ambos indicadores nos últimos anos do final da década (Montali, 2000b).

Ocorreram, nesse tipo de família, aumento do desemprego do chefe e redução na sua taxa de ocupação, sem que se tenha diminuído sua participação na força de trabalho. Diante da constante redução da taxa de ocupação do chefe, acentuada nos últimos anos da década, e do concomitante aumento da inserção da cônjuge em atividade de geração de renda, tem sido também crescente a participação desta na renda familiar. Ainda que a mulher-cônjuge representasse quase $30 \%$ dos ocupados da família em 1998 e 1999, sua contribuição para a renda familiar era cerca de $21 \%$ nesses anos, registrando crescimento, uma vez que representava 14,6\% em 1990, 18,9\% em 1994 e $19,5 \%$ em 1997. A contribuição dos parentes se mantém em todos os momentos inferior a 3\%. Nessa nova composição, a participação da renda do chefe decresceu de 81,9\% para $78 \%$ da renda familiar, entre 1990 e 1994, e reduziuse progressivamente, ficando em cerca de $76 \%$ nos três últimos anos (Gráficos 2 e 3).

O tipo de família "casal de até 34 anos com filhos" está relacionado ao momento de "constituição" do ciclo vital da família, etapa do nascimento da maior parte dos filhos. $\mathrm{O}$ arranjo de inserção no mercado observado decorre, em grande parte, da composição familiar típica dessa etapa do ciclo de vida da família e das atribuições sociais de seus componentes, pois praticamente só o casal está em idade para participar do mercado de trabalho, assim como à mulher cabe a atribuição social dominante do cuidado dos filhos.

Nesse tipo de família ocorreram tanto a redução na proporção do homem do casal entre os ocupados da família 


\section{GRÁFICO 2}

Distribuição dos Ocupados, por Posição na Família, segundo Tipologia de Família Região Metropolitana de São Paulo-1990-1999

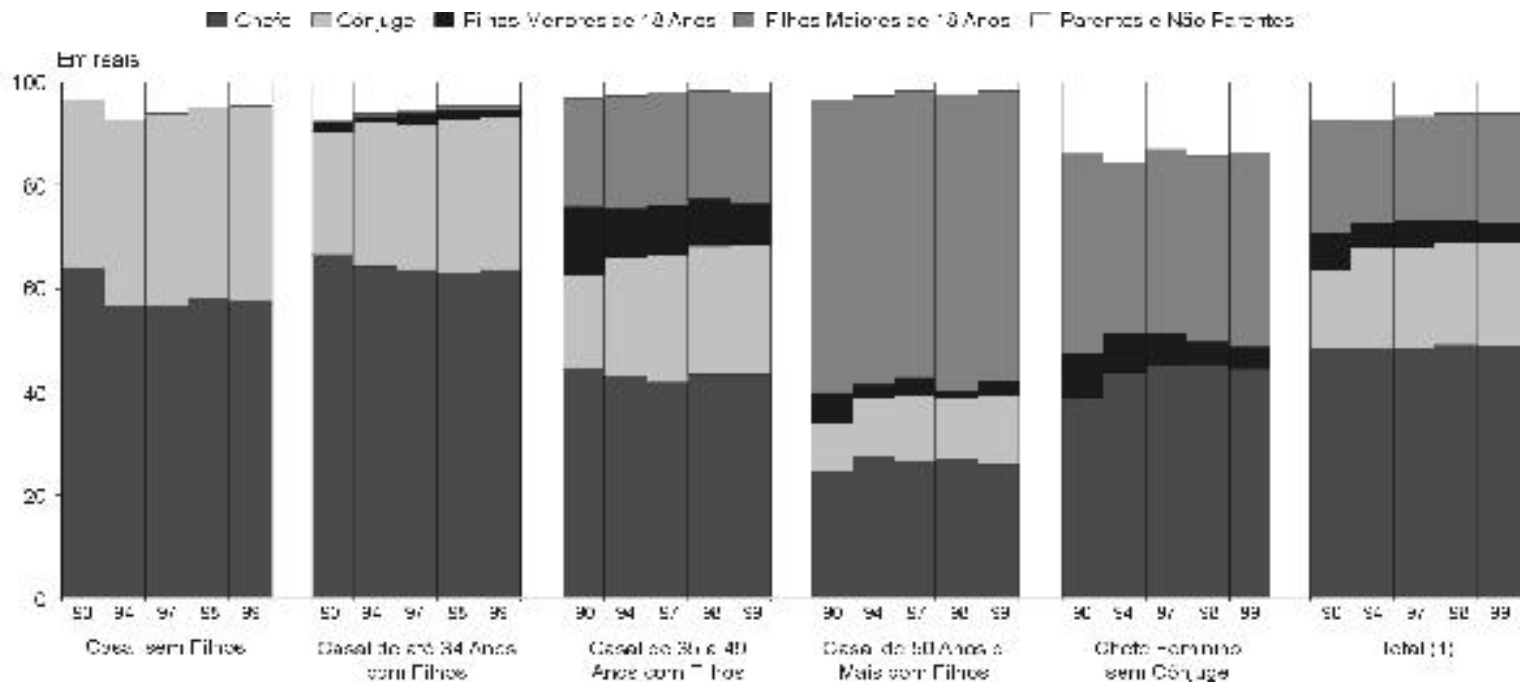

Fonte: Fundação Seade. Pesquisa de Condições de Vida - PCV 1990 e 1994; Fundação Seade - Dieese. Pesquisa de Emprego e Desemprego - PED 1997, 1998 e 1999 (trim. maio/jun./jul.). Elaboração: Montali (2000).

(1) Inclui outras configurações familiares.

\section{GRÁFICO 3}

Distribuição da Renda Familiar (1), por Posição na Família, segundo Tipologia de Família Região Metropolitana de São Paulo-1990-1999

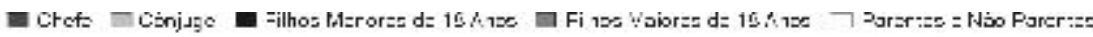

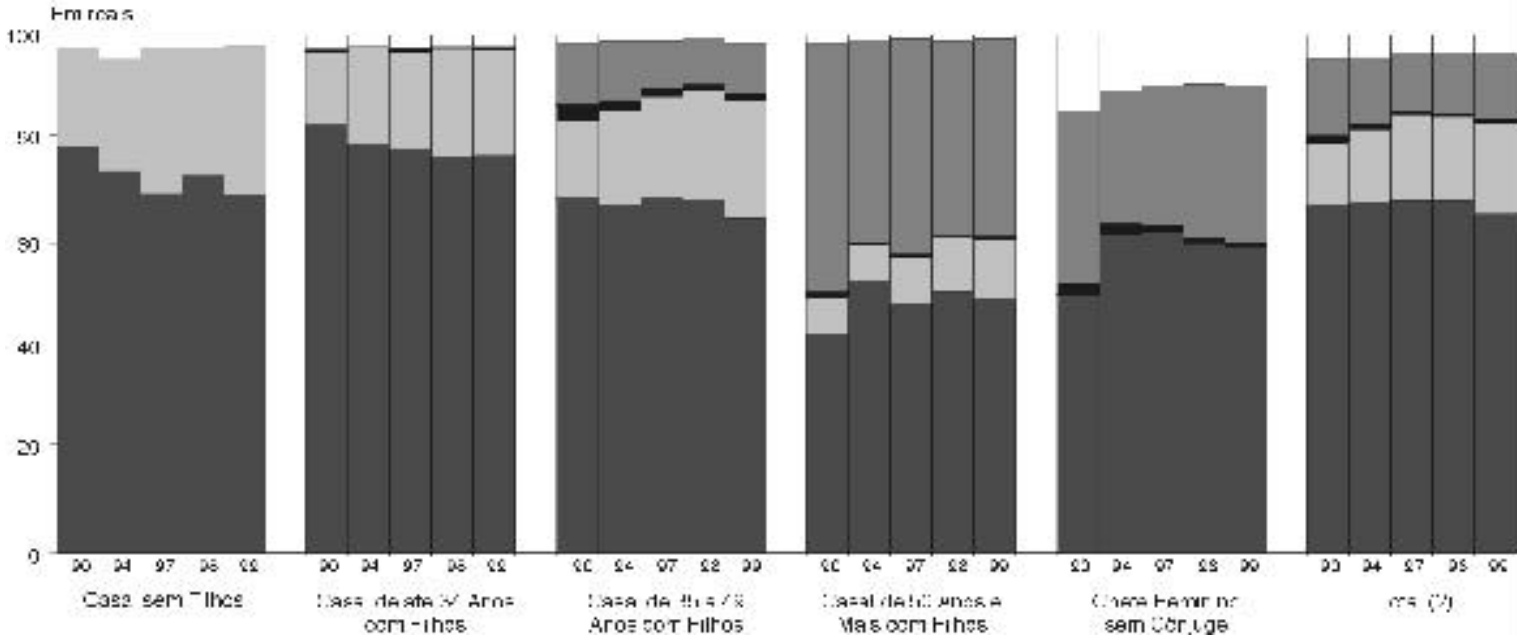

Fonte: Fundação Seade. Pesquisa de Condições de Vida - PCV 1990 e 1994; Fundação Seade - Dieese. Pesquisa de Emprego e Desemprego - PED 1997, 1998 e 1999 (trim. maio/jun./jul.). Elaboração: Montali (2000).

(1) Renda proveniente do trabalho. Participação na massa do rendimento familiar

(2) Inclui outras configurações familiares. 
como o progressivo crescimento da participação da mulher-cônjuge entre estes (Gráfico 2). Apesar desse movimento que atenua o encargo masculino da manutenção da casa, este permanece ainda bastante concentrado no componente masculino do casal, sendo o mais elevado entre os tipos de família. Entretanto, ao se comparar os padrões vigentes entre 1981 e 1994 e no ano de 1999, a tendência é de mudança na direção de um maior partilhamento na manutenção da família. $\mathrm{O}$ arranjo predominante apresentado por este tipo de família, em 1981, mostra o homem do casal como o responsável pela manutenção da família, quando representava $73 \%$ dos ocupados da família e a mulher respondia por $18,7 \%$, configurando, ao menos nesse aspecto, o modelo de família do chefe provedor. Desde 1990, define-se uma tendência de maior participação da mulher entre os ocupados da família, quando representar 24,2\% deles e o homem, 66,3\%. Em 1994, o homem responde por $64,3 \%$ dos ocupados da família e a mulher-cônjuge por $27,8 \%$ e, em $1999,63 \%$ e $30 \%$, respectivamente (Gráfico 2). Ainda que a contribuição para a renda familiar permaneça como atribuição do homem, a participação da mulher-cônjuge aumentou, passando de $15 \%$, em 1990 , para $20,5 \%$, em 1999 , enquanto a do homem diminuiu de $82 \%$ para $76,4 \%$ (Gráfico 3).

O tipo de família "casal de 35 a 49 anos com filhos" corresponde ao momento de "maturação", quando convivem no domicílio filhos de diferentes idades. Neste caso, o arranjo familiar de inserção é caracterizado pelo esforço coletivo dos componentes da família. O rearranjo de inserção no mercado de trabalho das famílias de casais entre 35 e 49 anos com filhos se dá com o aumento do desemprego, a redução nas taxas de ocupação do chefe e dos filhos e o crescimento na taxa de ocupação da cônjuge. Dessa maneira, a partir de 1994 diminuiu a participação dos dois primeiros entre os ocupados e aumentou a da cônjuge. Movimento semelhante se observa na contribuição de cada um desses componentes para a renda familiar (Montali, 1998, 2000b).

No final da década de 90, manteve-se esse padrão de arranjo familiar de inserção, diferenciando-se por apresentar crescente presença da mulher-cônjuge entre os ocupados e redução da proporção de filhos entre estes. Nas famílias desse tipo, a participação da cônjuge na composição da renda familiar aumentou de $14,3 \%$ para $17,4 \%$, entre 1990 e 1994, crescendo progressivamente, ainda que de maneira tênue, até o final da década, quando passou a representar 19,3\%, em 1997, e 21,8\%, em 1999 (Gráfico $3)$. A contribuição dos filhos maiores de 18 anos decres- ceu de $15,5 \%$, em 1990, para cerca de $11 \%$, no final da década. A participação do chefe na renda familiar, que era de 68\% desde 1990, reduziu-se para 65\%, em 1999 (Gráfico 3).

O arranjo de inserção dos componentes do tipo de família "casal de 50 anos e mais com filhos", na etapa de envelhecimento da família, é caracterizado pela maior presença dos filhos entre os ocupados, representando mais da metade destes do grupo doméstico. Entre 1990 e 1994, houve queda nessa participação, passando de $62,7 \%$ dos ocupados da família para 58,5\%, em decorrência da queda das taxas de participação para ambos os sexos e da acentuação das taxas de desemprego. Para enfrentar a situação de desemprego e a precarização do trabalho dos filhos adultos residentes, ocorreu o retorno para o mercado de trabalho de parcelas tanto do homem do casal central como da mulher-cônjuge. Esse movimento fica evidenciado pela expansão das taxas de participação do chefe com mais de 50 anos e das mulheres-cônjuge, bem como pela expansão das taxas de ocupação de ambos o que indica relativo sucesso na obtenção de ocupação, restando saber sobre a qualidade desta (Montali, 1998a).

Assim, entre 1990 e 1994, alteraram-se os pesos entre os componentes da família nesse arranjo familiar de inserção no mercado, diluindo tendencialmente o papel dos filhos como os principais mantenedores da família. No período 1997-99, com pequenas oscilações, manteve-se o arranjo de inserção familiar definido em 1994 (Gráfico 2). Os filhos representavam $63,9 \%$ dos ocupados em 1981 , $62,7 \%$ em 1990, 58,5\% em 1994 e cerca de 59\% no final da década. Em movimento inverso, cresceu a participação do chefe e da cônjuge idosos. Os primeiros correspondiam a 23,1\% dos ocupados em 1981, 24,6\% em 1990 e $27,4 \%$ em 1994, representando, nos dois últimos anos da década, cerca de $27 \%$. Acentuou-se a participação da cônjuge idosa entre os ocupados da família: eram 7,6\% em 1981, 9,4\% em 1990 e 11,4\% em 1994, passando para 12,9\% em 1997, 11,6\% em 1998 e $13 \%$ em 1999.

Como conseqüência desse rearranjo de inserção no mercado de trabalho, os casais mais velhos (50 anos e mais) aumentaram sua participação também na renda familiar, entre 1990 e 1994. A contribuição do chefe, que era de $42 \%$ em 1990, passou para $52 \%$ em 1994, com participação um pouco menor (cerca de 50\%) no final da década (Gráfico 3). A contribuição da cônjuge praticamente se manteve estável nos dois primeiros anos da década, ficando pouco acima 7\%; a partir de 1997, aumentou progressivamente, alcançando 12,3\% em 1999. 
Dessa maneira, no decorrer da década e respondendo à mudança do padrão de incorporação da força de trabalho após a intensificação da reestruturação produtiva, cresceu a importância do casal mais velho na composição da renda familiar, em grande parte decorrente do aumento da ocupação destes. Em 1990, o casal de 50 anos e mais contribuía com $49 \%$ da renda familiar e os filhos com $49 \%$, passando, respectivamente, para 59,7\% e 39,2\%, em 1994. Nos dois anos do final da década (1998 e 1999) aumentou novamente a contribuição do casal mais velho, respondendo por $61 \%$ da renda familiar e os filhos por $38 \%$ (Gráfico 3).

Assim, durante a década, a mudança que ocorreu no arranjo de inserção familiar desse tipo de família foi de redução da participação dos filhos na renda familiar, considerando que eram os principais mantenedores da família nos anos 80 e em 1990.

O arranjo de inserção no mercado de trabalho da família do tipo "chefe feminino sem cônjuge" apresenta também como característica o esforço coletivo. Esse tipo de família, em decorrência de sua composição, tem sofrido de maneira mais aguda os reflexos do novo padrão de absorção da força de trabalho que opera no mercado. Na família da chefe feminina sem cônjuge diminuiu a taxa de participação familiar, cresceu o desemprego e reduziu-se a taxa de ocupação, entre 1990 e 1994, mantendo o mesmo padrão em 1997 (Tabela 1). Agravou-se a situação de inserção deste tipo de família em 1998 e 1999, quando passou a apresentar mais elevadas taxas de desemprego da PEA familiar, da ordem de $22 \%$ e $23 \%$, respectivamente.

Nesse contexto, diante do elevado desemprego dos filhos e da queda na sua taxa de ocupação, aumentou o peso da chefe feminina entre os ocupados, passando de $38,8 \%$ para $43,7 \%$, entre 1990 e 1994 , e para cerca de $45 \%$, em 1997, 1998 e 1999. A participação dos filhos entre os ocupados diminuiu de $47,1 \%$ para 40,8\%, entre 1990 e 1994, e ficou em cerca de $41 \%$ nos anos finais da década (Gráfico 2).

Também nesse tipo de família ocorreu alteração no padrão verificado em 1981, 1983 e 1990. Observa-se que, a partir de 1994, como conseqüência do crescimento do desemprego especialmente para os jovens, a mulher-chefe assumiu a maior responsabilidade no encargo da manutenção da família. Cresceu a importância da renda obtida pela chefe mulher para a composição do rendimento familiar, que passou de $49 \%$, em 1994 , para $61,5 \%$, em 1994, diante da redução da contribuição dos filhos e parentes. Nos últimos anos da década, manteve-se esse mes- mo rearranjo na responsabilidade pela manutenção da família: em 1997, a mulher-chefe respondia por $62 \%$ da renda familiar e, em 1998 e 1999, devido à pequena recuperação na participação dos filhos, diminuiu para cerca de 60\% (Gráfico 3).

Este conjunto de informações evidenciou, através dos rearranjos de inserção no mercado efetivados nesse período de alteração do padrão de incorporação da força de trabalho, o maior partilhamento da responsabilidade pela manutenção da família entre seus diversos membros. Constatou-se também, ao examinar a participação efetiva dos rendimentos de cada um desses componentes na composição da renda familiar considerando o tipo de família, que esta corrobora as indicações anteriores acerca do maior partilhamento entre os componentes do grupo familiar das responsabilidades pela sua manutenção. A exceção se dá na família da chefe feminina sem cônjuge, na qual verificou-se movimento inverso de aumento do encargo para a mulher-chefe.

Outra constatação a ser ressaltada é que o aumento da importância da cônjuge entre os ocupados do tipo de família analisado acima resultou em crescimento significativo da sua contribuição na composição da renda familiar, ao serem comparados os anos estudados e os tipos de família (Gráfico 3).

Finalizando, foi possível demonstrar, através das análises apresentadas, que os arranjos e rearranjos de inserção no mercado de trabalho diferenciam-se entre os tipos de família e os momentos do ciclo vital das famílias. Os rearranjos possíveis de inserção no mercado de trabalho para os componentes da família são definidos por sua disponibilidade para o mercado de trabalho a partir de sua posição na família, relações de gênero e atribuições familiares, bem como pelos padrões vigentes de absorção da força de trabalho pelo mercado. Dessa maneira, como não existe "permutabilidade" nas possibilidades de inserção no mercado entre os componentes da família, porque são diferenciadas as restrições e o acesso ao emprego, os rearranjos de inserção possíveis nem sempre garantem ao grupo familiar a manutenção das condições de existência nos mesmos níveis. Assim, o desemprego e a precarização da ocupação dos principais mantenedores da família afetam a renda monetária disponível para suprir a sobrevivência da família.

Estes resultados de pesquisa reafirmam a hipótese de que as mudanças na divisão sexual do trabalho e nas relações hierárquicas estabelecidas na família passam pela impossibilidade concreta de realização do modelo do chefe 
provedor. Tanto os períodos de crise econômica como as alterações no padrão de incorporação da força de trabalho sob a reestruturação produtiva e organizacional na Região Metropolitana de São Paulo, analisados nas duas últimas décadas, evidenciam que vem se alterando a divisão sexual do trabalho no mercado, reforçam a impossibilidade de realização desse modelo de família e apontam para novas formas de divisão do trabalho que poderão, no futuro, impulsionar mudanças na divisão sexual do trabalho na família e nas relações internas de poder.

\section{NOTAS}

Este artigo foi apresentado em versão mais ampla no XXIV Encontro Anual da Anpocs - 2000, GT Família e Sociedade, sob o título "Mudanças recentes na relação família-trabalho". Traz resultados de pesquisa sobre os anos 90, projeto: "Família, Trabalho e Condições de Vida na Região Metropolitana de São Paulo: estudo da mudança na família e na relação família-trabalho no contexto da transformação das atividades econômicas", apoiado pelo CNPq na modalidade Projeto de Pesquisa Integrado desenvolvido junto ao Nepp/Unicamp. Os resultados apresentados baseiam-se em Montali (1998a, 2000b).

1. A periodização adotada pela pesquisa é a seguinte: 1981-83: recessão; 1984-86: recuperação e crescimento da atividade econômica; 1987-89: desaceleração da atividade econômica e superinflação; 1990-92: recessão (início da reestruturação produtiva na RMSP); 1993-96: recuperação sem recuperação do emprego; 1997-99: acentuação do desemprego na RMSP e baixo crescimento econômico; 2000: recuperação temporária do crescimento da economia.

2. Montali (1995), tese de doutorado, pesquisa realizada com apoio da Fapesp. Base de dados utilizada: Dieese. Pesquisa de Padrão de Vida e Emprego. Anos 1981 e 1983.

3. Outros estudos sobre a década de 80, tais como Jatobá (1990) e Fundação IBGE (1995), também mostraram o crescimento da participação de outros componentes da família além do chefe.

4. Montali (1998a), pesquisa realizada com apoio do CNPq. As bases de dados utilizadas são comparáveis à anterior: Fundação Seade. Pesquisa de Condições de Vida na Região Metropolitana de São Paulo. Bases dos anos 1990 e 1994

5. Tipologia de família construída com base na estruturação da família em torno de casal ou chefe sem cônjuge e momento do ciclo vital da família, definida nos estudos citados.

6. Montali (2000b), pesquisa realizada com apoio do CNPq. As bases de dados utilizadas são comparáveis à anterior: Fundação Seade. Pesquisa de Emprego e Desemprego - Região Metropolitana de São Paulo. Bases dos anos 1997, 1998 e 1999.

7. Maior detalhamento sobre as mudanças nas atividades econômicas na RMSP pode ser encontrado em Montali (1998b). Ver também Montali (2000c).

8. Pochmann (2001:110) considera que nas décadas de 80 e 90 houve desestruturação do mercado de trabalho na Região Metropolitana de São Paulo. Entende por desestruturação do mercado de trabalho "a presença simultânea e combinada do desemprego aberto em larga escala, do desassalariamento (redução dos empregos assalariados no total da ocupação) e da geração de postos de trabalho precários)".

9. A partir dos anos 80, acentuando-se nos anos 90, passaram a se concentrar na Região Metropolitana de São Paulo as sedes das principais empresas industriais e financeiras sediadas no Brasil.
10. Estes processos de transformação das atividades na RMSP, nos anos 80 e 90, foram objeto de muitos estudos, dentre os quais, Araujo (1992); Cordeiro (1993); Pacheco (1993); Bogus e Montali (1994); Cano e Semeghini (1991); Emplasa (1994); Véras (1996); Pochmann (2001).

11. As taxas de desemprego entre 1992 e 1997 são: 15,2\% (1992); $16,1 \%$ (1993); 15,3\% (1994); 13,5\% (1995); 15,9\% (1996); e 15,9\% (1997). Dados da Pesquisa de Emprego e Desemprego (PED) - Seade/ Dieese, referentes ao trimestre fevereiro, março, abril, utilizados para permitir a comparação com os dados de pesquisa de 1981 e 1983 (Dieese, PPVE). Fundação Seade. Boletim PED 122, 1996 e <www.seade.gov.br>.

12. Dados Dieese. PPVE (Pesquisa de Padrão de Vida e Emprego).

13. Tipologia de família construída a partir da estruturação das famílias - se nucleadas por casal ou por chefe sem a presença de cônjuge e das etapas do ciclo de vida familiar. São os seguintes os tipos de família utilizados: casais sem filhos, casais de até 34 anos com filhos residentes (etapa de constituição da família); casais de 35 a 49 anos com filhos residentes (etapa de consolidação da família); casais de 50 anos e mais com filhos residentes (etapa de envelhecimento da família); chefe feminino sem a presença de cônjuge (só, com filhos e/ou parentes); chefe masculino sem a presença de cônjuge (só, com filhos e/ou parentes).

\section{REFERÊNCIAS BIBLIOGRÁFICAS}

ABRAMO, L. Inserción laboral de las mujeres em America Latina: una fuerza de trabajo secundaria? Seminário temático interdisciplinar: Os estudos do trabalho; novas problemáticas, novas metodologias e novas áreas de pesquisa. Campinas: Unicamp, nov.dez. 2000.

. Imagens de gênero e políticas de recursos humanos na modernização produtiva. São Paulo em Perspectiva, São Paulo, Fundação Seade, v.11, n.1, p.110-121, 1997.

ARAUJO, M.F. Uma nova centralidade da Região Metropolitana de São Paulo. São Paulo em Perspectiva, São Paulo, Fundação Seade, v.6, n.3, p.55-59, 1992.

BARRÈRE-MAURISSON, M. La division familiale du travail - La vie en double. Paris: Presses Universitaires, 1992.

BOGUS, L.M.M.; MONTALI, L. A reestruturação metropolitana de São Paulo. Margem, São Paulo, Educ/Faculdade de Ciências Sociais da PUC, v.3, p.159-178, 1994.

BRANDÃO, S.M.C.; MONTAGNER, P. Novas características do desemprego. In: X ENCONTRO NACIONAL DE ESTUDOS POPULACIONAIS. Anais... Caxambu, Abep, 1996.

BRUSCHINI, M.C. O trabalho da mulher brasileira nas décadas recentes. In: II SEMINÁRIO NACIONAL: POLÍTICAS ECONÔMICAS, POBREZA E TRABALHO. Rio de Janeiro: Ipea, Série Seminários, n.7, 1994.

BRUSCHINI, M.C.; LOMBARDI, M.R. Trabalho feminino no Brasil no final do século: ocupações tradicionais e novas conquistas. In: SEMINÁRIO TEMÁTICO INTERDISCIPLINAR: OS ESTUDOS DO TRABALHO; NOVAS PROBLEMÁTICAS, NOVAS METODOLOGIAS E NOVAS ÁREAS DE PESQUISA. Campinas: Unicamp, nov./dez. 2000.

CANO, W.; SEMEGHINI, U.C. Setor terciário no Brasil: algumas reflexões sobre o período 1970/1989. In: IV ENCONTRO NACIONAL DA ANPUR. Anais... Salvador: Anpur, 1991.

CARDOSO, A. et al. Os deserdados da indústria. Reestruturação produtiva e trajetórias intersetoriais de trabalhadores demitidos da 
indústria brasileira. Revista Latinoamericana de Estudios Del Trabajo, Buenos Aires, ano 7, n.13, p.17-51, 2001.

CASTRO, N.A.; DEDECCA, C.S. (Orgs.). A ocupação na América Latina: tempos mais duros. Rio de Janeiro: Alast, 1998.

DEDECCA, C.S.; BALTAR, P.E. Precariedade ocupacional e relações de trabalho no Brasil nos anos 90. In: XXI CONGRESSO DA ASSOCIAÇÃO LATINO-AMERICANA DE SOCIOLOGIA. São Paulo: Alas, 1997.

DIEESE. Pesquisa Dieese - Emprego e Desemprego na Grande São Paulo. Conceitos, metodologia e principais resultados 1981-1983. São Paulo: Dieese, 1984.

DINI, N.P. et al. Renda familiar e distribuição de renda na RMSP nos anos 90: evolução conjuntural e seus determinantes. In: VI ENCONTRO NACIONAL DE ESTUDOS DO TRABALHO. São Paulo: Abet, 1999

FUNDAÇÃO SEADE - DIEESE. O mercado de trabalho na Região Metropolitana de São Paulo em 2000. São Paulo, 2001. Disponível em: 〈http://www.seade.gov.br〉. Acesso em: maio 2002.

. O mercado de trabalho na Região Metropolitana de São Paulo em 1999. São Paulo, 2000. Disponível em: <http://www.seade.gov.br>. Acesso em: fev. 2001.

. A população em idade ativa com experiência de trabalho nos anos 90 - Parte 1. São Paulo, 1998a. Disponível em: <http://www.seade.gov.br>. Acesso em: dez. 1999.

. O processo de mudança de emprego nos anos 90 - Parte 2. São Paulo, 1998b. Disponível em: 〈http://www.seade.gov.br〉. Acesso em: dez. 1999.

. Pesquisa de Emprego e Desemprego. São Paulo, 1995a. Disponível em: <http://www.seade.gov.br>.

. Boletim da Pesquisa de Emprego e Desemprego. São Paulo, 1995b. Disponível em: 〈http://www.seade.gov.br.>

GONZÁLEZ DE LA ROCHA, M. La reciprocidad amenazada: un costo mas de la pobreza urbana. Revista Latinoamericana de Estudios del Trabajo. Buenos Aires, ano 5, n.9, p.33-50, 1999.

. The erosion of a survival model: urban household responses to persistent poverty. In: WORKSHOP GENDER, POVERTY AND WELL-BEING: INDICATORS AND STRATEGIES. UNRISD, UNDP, CDS. Trivandrum, Kerala, november 1997.

HIRATA, H.; HUMPHREY, J. Nova divisão sexual do trabalho. Um olhar voltado para empresa e sociedade. São Paulo: Boitempo, 2002.

. Estruturas familiares e sistema produtivo: famílias operárias na crise. Tempo Social - Revista de Sociologia da USP, São Paulo, USP, v.4, n.1 e 2, p.111-131, 1994.

HIRATA, H.; HUMPHREY, J., HUSSON e ROLDÁN. Reestructuraciones productivas y cambios en la division sexual del trabajo y del empleo (Argentina, Brasil y Mexico). Sociologia del Trabajo. Nueva Epoca. Madri: Siglo XXI, v.24, 1995, p.75-97.

IBGE. Indicadores sociais: uma análise da década de 1980. Rio de Janeiro, 1995.

JATOBÁ, J. A família na força de trabalho: Brasil metropolitano 1978-1986. VII ENCONTRO NACIONAL DE ESTUDOS POPULACIONAIS. Anais... Campinas: Abep, 1990.
LAVINAS, L.; MATESCO, V.R. A reestruturação produtiva nas empresas brasilerias e seu reflexo sobre a força de trabalho por gênero. Rio de Janeiro: Ipea, 1996 (Texto para discussão 400).

LOBO, E.S. A classe operária tem dois sexos. São Paulo: Brasiliense/ SMC-PMSP, 1991

MATESCO, V.R. A dinâmica da reestruturação produtiva. Conjuntura Econômica, Rio de Janeiro, Fundação Getúlio Vargas, ano 49, n.5, p.48-51, 1995.

MONTALI, L. Família e trabalho: principais tendências no período 1985 a 2000. Crise, reestruturação produtiva e mudanças na relação família-trabalho. Campinas: Nepp/Unicamp, 2002 (Relatório de pesquisa)

. Família e trabalho na reestruturação produtiva: ausência de políticas de emprego e deterioração nas condições de vida. Revista Brasileira de Ciências Sociais, São Paulo, Anpocs, n.42, p.55-71, fev. 2000a.

Trabalho e familia no final dos anos 90: arranjos familiares de inserção e condições de vida sob o recrudescimento de desemprego. Campinas: Nepp/Unicamp, 2000b (Relatório de pesquisa).

Trabalho e família: reestruturação produtiva e mudanças na divisão sexual do trabalho nos anos 90. In: 3CONGRESSO LATINOAMERICANO DE SOCIOLOGIA DO TRABALHO Anais... Buenos Aires: Alast, maio 2000c.

Trabalho e família na Região Metropolitana de São Paulo na primeira metade dos anos 90: instabilidade e reestruturação produtiva. Campinas: Nepp/Unicamp, 1998 (Relatório final).

Familia e trabalho na conjuntura recessiva: crise econômica e mudança na divisão sexual do trabalho. 1995. Tese (Doutorado) - Departamento de Sociologia, Universidade de São Paulo, São Paulo, 1995.

MONTALI, L.; LOPES, G. Relações familiares e trabalho feminino na Região Metropolitana de São Paulo na década de 90. In: XIII ENCONTRO NACIONAL DA ABEP. Ouro Preto: Abep, 2002.

POCHMANN, M. A metrópole do trabalho. São Paulo: Brasiliense, 2001.

. Inserção ocupacional e o emprego dos jovens. Coleção Abet - Mercado de trabalho. São Paulo: Abet, v.6, 1998.

POSTHUMA, A.C.; LOMBARDI, M.R. Mercado de trabalho e exclusão social da força de trabalho feminina. São Paulo em Perspectiva, São Paulo, Fundação Seade, v.11, n.1, p.124-131, 1997.

TRONCOSO, E.L. Renda familiar e trabalho da mulher na Região Metropolitana de São Paulo nos anos 80 e 90. In: ROCHA, M.I.B. (Orgs.). Trabalho e gênero: mudanças, permanências e desafios. Campinas: Abep-Nepo/Unicamp e Cedeplar/UFMG, 2000. p.85110.

A expansão do emprego feminino, na Região Metropolitana de São Paulo, nos anos 90. In: XI ENCONTRO NACIONAL DE ESTUDOS POPULACIONAIS DA ABEP. Caxambu: Abep, 1998

Lilia Montali: Pesquisadora do Núcleo de Estudos em Políticas Públicas da Universidade de Campinas. 